\title{
A educação ambiental nos conteúdos de ecologia de livros didáticos de Biologia do Ensino Médio
}

\section{The environmental education in the content of ecology from biology teaching books in high school}

\author{
${ }^{1}$ Laísa Maria Freire laisapa@gmail.com \\ ${ }^{2}$ Ana Paula Neves dos Santos \\ ${ }^{3}$ Bianca Sarpa Miceli
}

\section{RESUMO}

O conhecimento ecológico é indispensável ao enfrentamento de problemas ambientais contudo, na sua relação com a Educação Ambiental (EA) tem sido alvo de críticas. Além disso, o livro didático (LD) tem histórica influência na seleção e organização dos conteúdos e métodos de ensino influenciando o trabalho do professor. Deste modo, buscamos olhar para os textos presentes em LD escolares do ensino médio e identificar onde e como a questão ambiental está apresentada; identificar temas ambientais presentes nos conteúdos de Ecologia e o tipo de abordagem da EA nos textos selecionados. Foram analisados dois LD do ensino médio a partir de análises de conteúdo. Caracterizamos as unidades de Ecologia nos livros e selecionamos dois textos complementares presentes no LD1 e um texto principal presente do LD2 para a análise de conteúdo e inferência sobre as abordagens da EA presentes no material. Os três textos selecionados foram escolhidos por terem um eixo comum "consumo”. Os resultados mostraram que os temas ambientais estão presentes nos LD, embora a maior parte esteja inserida em um “texto complementar” sendo apresentado como uma informação extra. Observou-se que vários textos presentes no livro se situam em macrotendências conservacionistas da EA, além de apresentar uma visão utilitarista, pragmática onde a natureza é vista apenas como uma fonte de recursos para o ser humano. Conclui-se que, embora as questões ambientais se façam presentes nos LD, a forma com que esses temas são apresentados compromete a formação de cidadãos ambiental e socialmente conscientes.

Palavras-chave: educação ambiental, ecologia, livro didático de ciências, análise de texto.

\begin{abstract}
The ecological knowledge is essential to solving environmental problems however, its relation to environmental education (EE) has been criticized. In addition, the textbook $(T B)$ has historical influence in the selection and organization of content and teaching methods and has influence the teacher's work. Thus, in this research we aim analyze texts present in high school TB and identify where and how environmental issues are presented; identify how environmental issues are present in the Ecology of content and what is the EA approach to selected texts. Two high school TB were analyzed using content analysis. We characterize the ecology units in the books and selected two complementary texts present in the TB1 and TB2 for the content analysis and inference on the approaches EA present in the material. The three selected texts were chosen because they have a common issue "consumption". The results showed that the environmental issues are present in the TB, while the greater part is inserted in a "accessory text" being displayed as an additional information. It was observed that several texts in the book are located in conservation macro trends of EE, while maintaining a utilitarian view, pragmatic where nature is seen only as a resource for humans. We conclude that while environmental issues to be present in the TB, the way these topics are presented it is not good for the formation of environmentally and socially conscious citizens.
\end{abstract}

Keywords: environmental education, ecology, science textbook, text analysis.

\footnotetext{
1 Laboratório de Limnologia, Departamento de Ecologia, Instituto de Biologia, Programa de Pós-graduação em Educação em Ciências e Saúde NUTES/UFRJ, Programa de Pós-graduação em Ciências Ambientais e Conservação -NUPEM/UFRJ.

2 Licenciada em Ciências Biológicas, Laboratório de Limnologia, Departamento de Ecologia, Instituto de Biologia.

3 Laboratório de Limnologia, Departamento de Ecologia, Instituto de Biologia, Programa de Pós-graduação em Educação em Ciências e Saúde - NUTES/UFRJ.
} 


\section{MOTIVAÇÃO DO ESTUDO E PROBLEMATIZAÇÃO INICIAL}

Atualmente é muito comum ouvirmos falar de Educação Ambiental (EA) e de como a escola pode e deve trabalhar o assunto, e isso parece estar presente não só no meio acadêmico e seus meios de comunicação, mas também nas políticas públicas que orientam a EA escolar. A partir de um olhar das políticas públicas educacionais, observamos que a EA faz parte dos temas transversais e situa-se especificamente no tema transversal Saúde e Ambiente (BRASIL, 1998). A proposta desta política é que os temas transversais deveriam ser abordados em diferentes disciplinas possibilitando ao aluno desenvolver uma visão geral do tema, porém o que se tem observado é que muitas vezes uma maior aproximação da disciplina de Ciências e/ou Biologia (OLIVEIRA, 2009) para tratar da EA na escola. A motivação da primeira autora pelo estudo surgiu em um contexto da disciplina de biologia, a partir do estágio de licenciatura com alunos do Ensino Médio de uma escola pública. Naquele momento, foi observado que as aulas de biologia eram focadas no conteúdo do livro didático (LD) e que quando o tema envolvia a EA, seu tratamento didático era priorizado nos capítulos de Ecologia do LD.

Podemos citar a influência do ambientalismo e das disciplinas Ecologia e Conservação na consolidação do campo da EA na década de 1980 contribuindo para um perfil inicial predominantemente conservacionista, com mais destaque para a esfera "ambiental” do que a "educacional” (LAYRARGUES; LIMA, 2011), nas ações de intervenção e nas pesquisas em EA. Begon et al. (2007) destacam o papel dos ecólogos e do conhecimento ecológico para a construção de um futuro sustentável. Os autores afirmam que "um futuro sustentável depende especialmente do conhecimento ecológico e da nossa capacidade de prever ou produzir consequências segundo diferentes cenários” (BEGON et al., 2007). Ainda, Santos et al. (2009, p.8) considera necessária a articulação entre diferentes conhecimentos econômicos, culturais e ecológicos para o enfrentamento dos problemas ambientais. Entende que:

a complexidade dos problemas ambientais determina que as influências socioeconômicas e culturais não podem ser ignoradas na dinâmica dos ecossistemas. Contudo, as decisões do manejo não podem ser tomadas sem a base ecológica.

Neste contexto, podemos reconhecer que na visão dos autores citados, de modo central ou articulado a outros conhecimentos, o conhecimento ecológico é indispensável ao enfrentamento de problemas ambientais. Através dele pode-se compreender a dinâmica dos ecossistemas, identificar problemas ambientais e suas relações em diferentes níveis organizacionais e construir referenciais para a tomada de decisões sobre a gestão de ambientes.

Contudo, no campo da EA partir da década de 1990, a discussão se apresenta de modo diferente. Podemos notar uma alteração desse perfil, ao menos entre os educadores ambientais próximos ao núcleo orientador do campo (LAYRARGUES; LIMA, 2011). Ou, ainda, na visão de autores como González-Gaudiano (2006) e Layrargues (2006) os diferentes sentidos da EA estão constantemente tensionados por disputas ideológicas. Assim, discussões recentes buscam considerar a EA crítica como a abordagem que geraria maiores possibilidades de mudanças socioambientais na estrutura da sociedade (SILVA, 2008). Deste modo, o presente estudo, fruto do trabalho de monografia de final de curso de licenciatura em Ciências Biológicas, discutiu as abordagens da EA e da questão ambiental nos conteúdos de Ecologia de livros de Biologia do Ensino Médio.

\section{1 A questão ambiental e as diferentes abordagens da EA}

Observando a trajetória do movimento ambientalista, vemos que a teoria e a prática de uma educação relacionada ao ambiente vêm sofrendo modificações importantes ao longo do tempo. Estas modificações constituem diferentes discursos e ideologias frente ao ambiental.

Martinez-Alier (2009) caracteriza as correntes do ambientalismo em três grandes grupos. Um deles é o culto ao silvestre que iniciou o caminho da crítica a sociedade moderna como um movimento em prol da conser- 
vação e preservação incondicional da natureza. Nessa corrente do ambientalismo, a natureza deve ser intocada, sendo o ser humano mais um elemento que a compõe, afastando-se de uma visão antropocêntrica e aproximando-se de uma visão biocêntrica.

Outra é a perspectiva do desenvolvimento sustentável aliado à corrente ambientalista "evangelho da ecoeficiência” (MARTINEZ-ALIER, 2009). Segundo o Relatório Brundtland ou "Nosso Futuro Comum” (1987), o conceito está relacionado à promoção de um desenvolvimento econômico e social aliado à conservação da natureza, de modo que o meio ambiente não seja "super-explorado", mas que consiga absorver os impactos do crescimento econômico sem que haja deteriorização. Neste sentido, o discurso orientador ratifica a capacidade do sistema de compatibilizar "desenvolvimento econômico e preservação ambiental”, desde que os indivíduos adotem posturas mais “respeitosas” para com a natureza (SILVA, ARAÚJO e SANTOS, 2012).

Uma terceira visão decorre do movimento de justiça ambiental que se caracteriza em um quadro de injustiça ambiental (LOUREIRO E LAYRARGUES, 2013), onde um grupo social com maior vulnerabilidade social e econômico é exposto a um risco ambiental, colocando em risco sua saúde e qualidade de vida. Layrargues e Lima (2011) acreditam que a injustiça social, associada às questões ambientais só podem ser enfrentados por meio da educação.

Relacionando as correntes do ambientalismo com visões de EA, temos no trabalho de Layarargues e Lima (2011) uma proposta de sistematização de macrotendências da EA. Para eles, no contexto das visões hegemônicas de EA, seja na ótica conservacionista ou na ótica pragmática (LAYARARGUES \& LIMA, 2011), o ambiente é tomado pelos seus aspectos naturais e favorece uma conceituação de EA, na qual ela funciona respectivamente tanto como ferramenta para a conservação ambiental, quanto como mecanismo pragmático de compensação do risco do atual modelo de produção e consumo. A visão conservacionista está centrada na conservação dos recursos naturais, notando-se um distanciamento entre o ser humano e a natureza a fim de preservá-la. O ser humano é visto como o destruidor da natureza, e os problemas ambientais são discutidos de forma superficial, sem considerar o seu contexto social, político, cultural e histórico. Na visão pragmática, o consumo deve ser sustentável, bem como o desenvolvimento. Contudo, outras dimensões podem estar envolvidas a partir de uma visão mais questionadora destas relações do ser humano com o meio ambiente. Uma abordagem crítica da EA busca “o enfrentamento político das desigualdades e da injustiça socioambiental” (LAYARARGUES \& LIMA, 2011), apoiada em teorias do campo da sociologia, da política, da economia. Essa perspectiva entende que os problemas ambientais são oriundos da estrutura social e questiona a estrutura de acumulação do capital como forma de solucionar esses problemas. Deste modo, surge uma questão importante para se investigar dada a polissemia do campo de EA (SORRENTINO, 2002; SAUVÉ, 2005; LAYRARGUES, 2006; SILVA, 2008; SILVA E CAMPINA, 2009) o que leva a diferentes abordagens de EA e disputas nessa área (GONZÁLEZ-GAUDIANO, 2006; LAYRARGUES, 2006).

A partir desta problematização inicial e considerando que o livro didático de Ciências e Biologia presente na rotina escolar, tem histórica influência na seleção e organização dos conteúdos e métodos de ensino influenciando o trabalho do professor (SELLES E FERREIRA, 2004), buscamos olhar para os textos presentes em livros didáticos escolares e discutir a seguinte questão de pesquisa: De que modo a EA é abordada nos livros didáticos de Biologia destinados aos estudantes do Ensino Médio? Além desta, as questões subjacentes: se a EA é apresentada no LD principalmente vinculada aos conteúdos ecológicos, haveria a macrotendência conservacionista da EA sendo privilegiada? Que implicações esta abordagem poderia trazer para o campo da EA e para as práticas educativas? Para isso, apresentamos três objetivos: (i) identificar onde e como a questão ambiental está inserida nos livros didáticos; (ii) identificar temas ambientais presentes nos conteúdos de Ecologia (iii) identificar o tipo de abordagem da EA nos textos selecionados dos capítulos de Ecologia. 


\section{PROCEDIMENTOS METODOLÓGICOS}

A primeira etapa para a análise foi a seleção dos livros didáticos. Os dois livros selecionados fazem parte da lista de indicação do PNLD do ano de 2009 para o Ensino Médio. Os dois livros selecionados são volumes únicos que englobam o conteúdo dos três anos do Ensino Médio e a denominação de LD 1 (Biologia, Sérgio Linhares e Fernando Gewandsznajder, Editora Ática, ano 2008) e LD 2 (Biologia, Sônia Lopes e Sérgio Rosso, Editora Saraiva, ano 2005).

Como a questão ambiental não se configura em uma disciplina específica, e nem está restrita a uma unidade especifica dentro das disciplinas, ela deve estar inserida em diferentes contextos. Na disciplina de Biologia, embora a temática ambiental esteja mais presente nas unidades referentes à Ecologia, este trabalho buscou fazer uma leitura inicial de todos os capítulos presentes no livro, procurando qualquer referência ao tema. Deste modo, foram identificadas referências à questão ambiental no texto principal, texto complementar ou atividades, por meio de busca de palavras. Vale ressaltar que a questão ambiental aqui está sendo considerada de forma ampla, entendendo o ambiente como espaço de disputas e, portanto considerando que a dimensão social, cultural, política, econômica, etc., é parte da questão ambiental em geral.

Para respondermos a questão de pesquisa, colocada, escolhemos a unidade de Ecologia de modo a analisar a visão de EA na relação com os conteúdos ecológicos dos livros. Deste modo, caracterizamos as unidades de Ecologia nos livros, tanto nos textos principais, quanto nos textos complementares para buscarmos a relação com outras abordagens de EA. Dentro dessas unidades foram selecionados dois textos complementares presentes no LD1 e um texto principal presente do LD2 para a análise de conteúdo e inferência sobre as abordagens da EA presentes no material. Os três textos selecionados foram escolhidos por terem um eixo comum "consumo", que pode ser tratado não só na perspectiva ecológica, mas também ambiental em geral. Deste ponto de vista mais amplo, do tema consumo, entendemos "sociedade de consumo" como um assunto agudo nos dias atuais e a produção de qualquer produto acaba de alguma forma gerando um impacto no meio ambiente, seja na extração da matéria prima, no processo de produção ou no seu descarte. Além disso, um dilema da sociedade capitalista, é que a cidadania muitas vezes caba ficando atrelada à questão do consumo, da inserção e do status social. Assim, a análise textualmente orientada buscou identificar o tipo de abordagem de EA presente nesses textos sobre consumo nas unidades de Ecologia.

\section{RESULTADOS}

\section{1 Aspectos Gerais dos livros didáticos}

O LD 1 é dividido em nove unidades e essas são divididas em 54 capítulos, mais um capítulo especial sobre drogas. Além do texto principal, os capítulos apresentam textos complementares inseridos em quadros, com uma cor diferente que os destaca do resto do conteúdo. Esses textos extras abordam questões ligadas a saúde, tecnologia, cotidiano, trabalho, cultura entre outros. O livro apresenta também uma seção chamada “Aplique seus conhecimentos" na qual há textos complementares acompanhados de atividades. Apresenta ilustrações, com imagens, esquemas e fotografias, e os exercícios frequentemente apresentam gráficos e tabelas.

Em todo o livro sempre que aparece uma palavra nova, desconhecida pelos alunos ou considerada pelos autores de difícil entendimento, esta é marcada em negrito. Nas páginas finais do livro, há um glossário com a definição de todas as palavras marcadas. Ao fim de cada capítulo, o livro apresenta uma série de exercícios que são divididos em cinco tipos: "Compreendendo o texto", "Atividade em grupo", "Refletindo e concluindo", “Questões para análise” e "Exame Nacional do Ensino Médio”. Em alguns capítulos o livro também apresenta uma sugestão de experimento. 
O LD 2 é dividido em sete unidades, que se desdobram em 41 capítulos. É ilustrado com imagens fotográficas, ilustrações e esquemas. Inserido nos textos principais, há vários textos complementares que aparecem em destaque com cores diferentes. Ao final de cada capítulo existe um "texto para discussão" seguido de uma atividade. O livro não apresenta glossário. Os exercícios apresentados são divididos em três categorias: "Questões para estudo”, "testes” e "Questão discursiva”. Nenhum tipo de atividade experimental foi encontrado no LD2.

\section{2 A questão ambiental nos livros analisados}

A questão ambiental aparece retratada de alguma forma nos livros analisados contudo, em geral, não faz parte do texto principal. Ela aparece em quadros separados, geralmente de outra cor, como sendo uma informação extra. Alguns destes textos extras são acompanhados de atividades.

Excetuando-se os capítulos que fazem parte da unidade Ecologia, não são frequentes referências às questões ambientais nas listas de exercícios. Quando são apresentados exercícios sobre os temas ambientais, estes geralmente fazem parte das questões retiradas de vestibulares e do ENEM. O LD1 frequentemente apresenta questões ambientais em sua atividade denominada “Atividade em grupo" na qual são sugeridos temas para que os alunos façam uma pesquisa em grupo.

O quadro a seguir relaciona temas da questão ambiental abordada nos livros analisados ao local no LD. O quadro apresenta o capítulo do qual o conteúdo faz parte, a temática abordada, se essa temática está inserida no texto principal ou faz parte de um texto extra, e a presença ou ausência de atividades. 
Quadro 1 - Localização dos conteúdos ambientais apresentados pelo LD1 e LD2.

\begin{tabular}{|c|c|c|c|c|}
\hline Capitulo & Temática abordada & \begin{tabular}{|l|} 
Texto \\
Principal
\end{tabular} & \begin{tabular}{|l|} 
Texto \\
Extra
\end{tabular} & $\begin{array}{l}\text { Apresenta } \\
\text { Atividade }\end{array}$ \\
\hline \multicolumn{5}{|c|}{ Livro didático 1} \\
\hline 9 & Transgênicos & $\mathrm{X}$ & - & Sim \\
\hline $16 ; 17$ е 18 & $\begin{array}{l}\text { Importância do saneamento básico na prevenção de doenças causadas } \\
\text { por vírus, bactérias e protistas }\end{array}$ & $\mathrm{X}$ & - & Sim \\
\hline 18 & Maré vermelha & - & $\mathrm{X}$ & Sim \\
\hline 20 & Importância das algas & - & $\mathrm{X}$ & Sim \\
\hline 22 & Exploração para a extração da madeira & $\mathrm{X}$ & - & Não \\
\hline 23 e 24 & Saneamento e higiene na prevenção de verminoses & $\mathrm{X}$ & - & Sim \\
\hline 22 & Hidroponia & - & $\mathrm{X}$ & Não \\
\hline 23 & Água limpa e esgoto & - & $\mathrm{X}$ & Sim \\
\hline 23 & Recife de corais & - & $\mathrm{X}$ & Sim \\
\hline 38 & A $2^{\circ}$ lei de Mendel e a agricultura & - & $\mathrm{X}$ & Sim \\
\hline 45 & Raças na espécie humana? & - & $\mathrm{X}$ & Sim \\
\hline \multicolumn{5}{|c|}{ Livro didático 2} \\
\hline 1 & O equilíbrio da natureza & - & $\mathrm{X}$ & Sim \\
\hline 2 & $\begin{array}{l}\text { Harmonia e respeito entre seres humanos e natureza: uma questão de } \\
\text { vida }\end{array}$ & - & $\mathrm{X}$ & Sim \\
\hline 9 & Filhos, uma decisão responsável & - & $\mathrm{X}$ & Sim \\
\hline 9 & Por que amamentar? & - & $\mathrm{X}$ & Sim \\
\hline $13 ; 14$ e 15 & $\begin{array}{l}\text { Saneamento e higiene na prevenção de doenças causadas por vitus, } \\
\text { bactérias e protistas }\end{array}$ & $\mathrm{X}$ & - & Sim \\
\hline 14 & Bactérias na resolução de problemas de esgoto e lixo & - & $\mathrm{X}$ & Sim \\
\hline 15 & Malária, sério problema de saúde publica & - & $\mathrm{X}$ & Sim \\
\hline 16 & Fungos - heróis ou vilões da biosfera & & $\mathrm{X}$ & Sim \\
\hline 17 & Exploração da madeira & $\mathrm{X}$ & & Não \\
\hline 17 & Impactos das plantas transgênicas no sistema de produção de alimentos & - & $\mathrm{X}$ & Sim \\
\hline 19 & Um triste exemplo de conhecimento biológico mal utilizado & - & $\mathrm{X}$ & Sim \\
\hline 20 & As esponjas e sua importância médica, ecologia e econômica & - & $\mathrm{X}$ & Sim \\
\hline 21 & Saneamento e higiene na prevenção de verminoses & $\mathrm{X}$ & - & Sim \\
\hline 25 & Projeto Tamar & - & $\mathrm{X}$ & Não \\
\hline 37 & A evolução da cultura humana & - & $\mathrm{X}$ & Não \\
\hline
\end{tabular}

Legenda: X: indica que a temática esta apresentada nessa categoria

- : indica que não há menção da temática nessa categoria

Sim: indica que a temática apresenta atividades

Não: indicia que a temática não apresenta atividades

É possível notar em vários textos e atividades uma visão utilitarista da natureza. Como exemplo, uma atividade que se encontra junto ao texto "Importância das algas” apresentada na página 178 do LD1. A atividade cita algumas espécies de algas encontradas em diferentes regiões do Brasil e pede ao aluno que responda: "Que produtos podem ser extraídos dessas algas?” Essa atividade sugere que a importância das algas se deve somente para a extração de substâncias para o uso humano.

Em relação às atividades propostas nos livros analisados, as mesmas não faziam relações explícitas com a EA. Em toda a unidade de Ecologia, em ambos os livros, a maior parte das atividades estão mesmo relacionadas à verificação da aprendizagem quanto aos conteúdos ecológicos, como por exemplo, ciclos biogeoquímicos, tipos de biomas e relações intra e interespecíficas. Em grande parte das atividades propostas, o aluno pode encontrar as respostas no próprio texto, não sendo necessário pesquisar em outras fontes. O LD1 apresenta em 
alguns capítulos uma sugestão de atividade em grupo, e nesse caso o aluno é obrigado a utilizar outras fontes de pesquisa. No LD2 não há nenhum tipo de atividade sugerindo uma pesquisa em grupo.

No LD1, nove dos textos complementares pertencentes a unidade Ecologia são acompanhados por atividades. No LD2 essa frequência é menor, sendo que apenas quatro dos textos presentes possuem atividades. No geral, essas atividades são compostas por uma ou duas questões discursivas referentes ao assunto abordado no texto complementar e neste caso, as questões de EA se fazem presentes na maior parte dos textos. É interessante ressaltar que nesse tipo de atividade as respostas não estão evidentes no texto. Elas devem ser obtidas através da reflexão do aluno e dos debates em sala de aula, o que nos permite concluir que a abordagem está muito dependente do trabalho do docente em sala de aula.

\section{3 Análise geral da unidade Ecologia}

O parágrafo introdutório da ecologia no LD1 se limita a apresentar o significado da palavra ecologia e o que ela estuda, como observado no fragmento a seguir: "A Ecologia (oikos = casa e, por extensão ambiente; logos = estudo) é a ciência que estuda como os seres vivos se relacionam entre si e com o meio ambiente em que vivem $e$ quais as consequências dessas relações”. (LD1, p. 451). Já no LD2, além do concito de ecologia, há preocupação utilitária do conhecimento ecológico no enfrentamento de problemas ambientais. Vejamos o fragmento:

A ecologia é uma área da Biologia que se preocupa em estudar as relações entre os seres vivos e entre eles e o meio em que vivem. Essa área está em pleno desenvolvimento e se torna cada vez mais importante por causa da interferência humana sobre os ecossistemas”. (LD2 p.540)

O texto apresentado no LD2 segue expondo conteúdos sobre a interferência humana, e em uma visão antropocêntrica da relação entre o ser humano e natureza. Apresenta em destaque um trecho adaptado do livro de Jean Dorst, Antes que a natureza morra, de 1973: “A natureza não deve ser salva para rechaçar o ser humano, mas sim porque a salvação dela constitui a única probabilidade de sobrevivência material para a humanidade, devido a unidade fundamental do mundo em que vivemos”. (LD2, p. 540).

O conteúdo textual de ambos os livros abordam a ecologia dos ecossistemas, os ciclos biogeoquímicos, os biomas do Brasil e do mundo e os tipos de poluição. Gomes (2008) descreve duas perspectivas de enfoque curricular de ecologia: (i) as percepções da ciência e seu ensino referenciadas no campo da ecologia biológica com seus métodos de trabalho incluindo tanto os conhecimentos das populações e comunidades como aqueles dos ecossistemas e (ii) as percepções relacionadas a movimentos ambientalistas, principalmente aqueles relacionados à Educação Ambiental com finalidades de promover nos estudantes interesses pelas problemáticas ambientais. No caso dos livros didáticos analisados, não há enfoque curricular de ecologia voltado para a problematização das questões ambientais.

É interessante ressaltar que no capítulo destinado à poluição, o LD 1 apresenta exemplos de problemas decorrentes de cada agente poluidor, como por exemplo: inversão térmica, eutrofização, destruição do solo entre outros, seguido de uma lista com soluções que deveriam ser adotadas para acabar ou ameninar os danos causados. Porém, em todos os tipos de poluição, com exceção do lixo, as soluções apresentadas dependem dos governos e/ou das indústrias como, por exemplo: implantação de áreas verdes, instalação de filtros e equipamentos antipoluentes nas indústrias, fiscalização e multa de veículos com motor desregulados, construção de mais biodigestores, controle da poluição nos garimpos, etc.

As soluções apresentadas são importantes, pois mostram ao aluno o papel de cada ator no combate aos diversos tipos de poluição, porém poderia ser complementado com medidas que a população pode adotar no dia a dia para amenizar o problema. No texto analisado, somente na parte destinada a poluição causada pelo lixo, 
é que pode-se observar medidas cabíveis a população como: evitar sacolas plásticas de loja e supermercados, evitar produtos descartáveis, sempre que possível doar ou restaurar roupas, brinquedos e utensílios etc.

Da mesma maneira que os capítulos que compõem os livros analisados, muitos dos textos que fazem parte da unidade da Ecologia apresentam uma visão utilitarista do ambiente. Como exemplo, temos a página 523 do LD1 que disserta sobre a destruição da biodiversidade. Apresentamos alguns trechos do texto que nos permitem ter essa visão utilitarista: "Com a extinção de uma espécie, perdem-se sua informação genética e as substancias potencialmente úteis à humanidade”. Também o seguinte trecho: "Não podemos esquecer também os benefícios estéticos da conservação das espécies, que podem gerar benefícios econômicos, como em vários países africanos que usam sua fauna para o ecoturismo".

Dessa forma, o texto leva a uma construção ideológica de que é preciso preservar a biodiversidade para que o homem possa continuar desfrutando dela, num sentido de extração de seus recursos. A natureza é vista como uma espécie de "mercado" no qual o homem adquire os produtos que precisa para viver e gerar cada vez mais lucro. Segundo Gerent (2011, p. 29):

\footnotetext{
“a preocupação em preservar o ambiente natural não deve advir apenas de sua utilidade como recurso natural para o homem, mas, também, por seu valor intrínseco, isto é, o reconhecimento de que a Terra e todos que nela habitam, seres vivos, racionais ou não, e seres não vivos tem importância para a manutenção da qualidade de vida e do equilíbrio ecológico”.
}

Assim como nas demais unidades que compõem os livros, cada capítulo da unidade Ecologia também apresenta textos complementares, que abordam temas importantes e atuais. Geralmente esses textos são acompanhados por uma atividade dissertativa, que leva o aluno a refletir sobre o tema abordado. Foram encontrados 10 temas complementares no LD1 e 10 no LD2 nas unidades de Ecologia. Todos os textos apresentados fazem referência ao tema do capítulo no qual estão inseridos. A partir da leitura dos textos, percebeu-se que os textos abordam três questões principais: consumo e desperdício; interferência humana; e fenômenos naturais. Neste trabalho optamos por um recorte no tema consumo e desperdício para análise mais aprofundada de cada texto.

\section{4 Aprofundando os resultados: análise do tema consumo nos capítulos de Ecologia e sua relação com a Educação Ambiental}

A seguir apresentamos os três textos selecionados e que abordam o tema consumo.

\subsubsection{Salvando a Terra - LD 1}

No texto "Salvando a Terra" os autores abordam o tema da má distribuição dos recursos em nosso planeta, assim como a crescente sociedade de consumo em que vive. O texto está situado no final do capítulo que trata dos ciclos biogeoquímicos e busca fazer uma reflexão sobre o uso dos recursos naturais. Para isso apresenta, por meio de porcentagens, a existência de uma má distribuição dos recursos e um consumo incompatível entre as classes ricas e pobres. Questões sociais aparecem em termos de desigualdade de acesso, no primeiro parágrafo, mas no segundo, quando os autores apresentam possíveis estratégias para a preservação dos recursos, as classes, as divisões entre pobres e ricos desaparecem. As soluções apresentadas parecem ser independentes do acesso ao recurso.

Um ponto que se destaca é a informação contida no texto de que o desenvolvimento sustentável é "um desenvolvimento que atenda às necessidades atuais do ser humano sem colocar em perigo a capacidade de as gerações futuras continuarem a se desenvolver". Neste sentido os autores passam a ideia de que única razão para se adotar um consumo sustentável é permitir que as gerações (humanas) do futuro possam continuar se desenvolvendo (explorando o meio ambiente). Em nenhum momento o texto faz referência a preservação ambiental sem que esta 
esteja relacionada com a utilidade da natureza para o homem. Essa perspectiva vai de encontro a uma das correntes do ambientalismo conforme proposto por Martinez-Alier (2009). Segundo o evangelho da ecoeficiência seria possível aliar o desenvolvimento econômico, que o capitalismo necessita, à conservação da natureza.

Sobre a expressão apresentada “desenvolvimento sustentável”, alguns autores afirmam que o termo mais apropriado seria “sociedade sustentável”. Para Loureiro (2012) o termo “desenvolvimento” é entendido como algo linear, evolucionista e universal. Neste sentido o uso o termo "sociedades sustentáveis" refere-se "à negação da possibilidade de existir um único modelo ideal de felicidade e bem-estar a ser alcançado por meio do desenvolvimento". Dessa maneira, nem toda a sociedade terá os usufrutos do desenvolvimento e uma parcela, principalmente os mais pobres, acabará sofrendo as consequências do sistema, o que gera desigualdades sociais e de acesso.

O texto cita que é necessário “diminuir o consumo de supérfluos”, mas essa é uma questão variável, pois não se pode definir o que é básico e o que é supérfluo para a toda a população de uma forma geral. De acordo com o Manual de Educação para o Consumo Sustentável (2005, p. 15) “a definição de necessidades básicas e supérfluas está intimamente ligada às características culturais da sociedade e do grupo a que pertencemos. $O$ que é básico para uns pode ser supérfluo para outros e vice-versa”. Além disso, é preciso ter cuidado ao afirmar que é preciso diminuir o consumo, uma vez que determinadas classes que historicamente não tinham o acesso ao consumo, ao terem o poder de compra, tem o direito de consumir. Nesse sentido, cabe-nos refletir sobre a vinculação da noção de cidadania com o consumo, tendo em mente que a nossa sociedade valoriza esse consumo.

A última sentença do parágrafo do texto cita a importância dos tratados internacionais para proteger o meio ambiente, criando novas áreas de proteção e expandindo as já existentes. A partir dessa informação tem-se a ideia de que a única forma de se preservar o meio ambiente é através da criação de áreas de proteção ambiental. Esta ideia está ancorada na corrente do ecologismo culto ao silvestre (MARTINEZ-ALIER, 2007) e macrotendências conservacionistas da EA. De acordo com Loureiro et al (2009), o culto ao silvestre busca manter as reservas naturais livres da interferência humana e está estruturado na biologia da conservação, assumindo uma posição utilitarista na medida em que aceita a importância do conhecimento e o uso da biodiversidade.

Assim, apesar do título "Salvando a Terra", o texto não apresenta meios consistentes para isso. O texto se inicia trazendo informações quantitativas em relação a diferença de consumo entre ricos e pobres, mas em nenhum momento é abordado como se pode atuar em sociedade para diminuição das assimetrias sociais. No segundo parágrafo, o texto tem sua discussão voltada para as atitudes que levariam ao desenvolvimento sustentável, assumindo uma posição do evangelho da ecoeficiência (MARTINEZ-ALIER, 2007) que se vincula a macrotendências pragmáticas da EA. Em síntese, podemos dizer que o texto oscila entre duas visões hegemônicas da relação entre o ser humano e o meio ambiente, mas ancoradas no conservacionismo.

\subsubsection{Crescimento da população humana - LD 1}

O texto “Crescimento da população humana” está inserido no capitulo que aborda o tema de populações ecológicas. Os autores buscam neste texto trabalhar as populações humanas. O tema central considera o fato de que os avanços científicos e econômicos ocorridos nas últimas décadas elevaram a expectativa de vida, mas geraram um aumento da população humana. O texto apresenta características da abordagem crítica que pode ser percebida quando cita-se como causa do uso inadequado do solo e dos recursos hídricos "a ignorância ou a busca de lucro rápido”. Porém, o texto não esclarece que ignorância seria essa, nem da parte de quem. No mesmo sentido o texto cita que é preciso "garantir um padrão de vida adequado para todos", "melhorar o nível de vida de toda a população" e ainda elevar a "qualidade de vida”, mas em nenhum momento esclarece que melhorias seriam essas ou qual é o padrão de vida adequado para todos. Será que só existe um único padrão de vida que seja adequado para toda a população mundial? Dessa maneira, o texto não considera as questões culturais, sociais, políticas e regionais, caracterizando uma abordagem conservacionista. 
Outra questão mais problematizada que se vincularia a abordagens mais críticas da questão ambiental e que aparece no texto é a de que a superpopulação não pode ser apontada como a única causa da fome, miséria e degradação ambiental. Neste sentido, Foladori (1999) afirma que a pobreza e o incremento populacional são consequências das relações capitalistas. Segundo este autor "A produção capitalista inaugura, pela primeira vez na história da humanidade, um sistema de produção cujo objetivo não é a satisfação direta das necessidades, mas a obtenção de um lucro em dinheiro". O foco lucrativo e desenvolvimentista do sistema capitalista gera, como consequência, ampliação das desigualdades sociais no que diz respeito ao acesso aos recursos sejam eles materiais ou ambientais.

Embora considere que a má distribuição de renda e os hábitos de consumo das populações ricas sejam fatores que contribuem para a pobreza e os problemas sociais, o texto cita que a maioria dos cientistas concorda que se deve "desacelerar o crescimento populacional de forma a estabilizar a população em um ponto compatível com os recursos do planeta." Essa frase acaba por transmitir uma ideia quantitativa, de forma que basta diminuir o número de pessoas para se alcançar uma estabilidade entre a população humana e os recursos naturais. Mais uma vez o texto não considera as diferenças de consumo existentes na população humana.

Outro ponto analisado, é que o texto se inicia com a informação de que os avanços técnicos e científicos, como medicina, saneamento, conservação de alimentos e vacinação são fatores responsáveis para o exponencial aumento da população humana. Posteriormente, o texto afirma que $97 \%$ do crescimento populacional acontece nos países mais pobres, causando assim um contraste de ideias que pode gerar dúvidas nos alunos. Se a causa do crescimento populacional são as melhores condições de vida promovidas pelos avanços técnicos e científicos, por que as taxas mais altas de crescimento são vistas em países onde esses avanços praticamente não existem? O texto não cita as questões históricas, econômicas e culturais que fazem com que as taxas de crescimento da população sejam diferentes entre as várias regiões do planeta.

Nessa perspectiva, Cunha (2012) destaca que não se deve culpar a superpopulação de pobres pelos impasses decorrentes do crescimento populacional. Segundo Cunha, "o problema não é que os pobres são muitos. O problema é que eles têm pouco”. No mesmo artigo o professor Alisson Barbieri cita que a África é a região onde a população mais cresce no mundo, mas lá as condições de vida são tão precárias que a produção de lixo, consumo de energia e outros dispêndios é mínima se comparada com países desenvolvidos. Barbieri considera que na discussão sobre o crescimento da população, o tamanho da população é um fator secundário, pois "mais importante que a quantidade de pessoas no planeta, é a maneira como as pessoas vivem e a forma como a sociedade se organiza para produzir e consumir.”.

No último parágrafo o texto fala da necessidade de um "controle voluntário da natalidade" e destaca a importância da informação e de assistência média nesse processo. Embora o utilize a palavra "voluntário”, o termo mais adequado seria "planejamento familiar". Segundo Anacleto et al (2010), planejamento familiar é "o direito a informação, à assistência especializada e acesso aos recursos que permitam optar livre e conscientemente por ter ou não filhos, o número, o espaçamento entre eles e o método anticoncepcional mais adequado, sem coação". Por outro lado o controle de natalidade é a "ação governamental com a preocupação de estipular metas de crescimento "ideal" da população, quer dizer, o governo determina quantos filhos o casal deve ter".

\subsubsection{O lixo - LD 2}

O texto "O lixo" não é um texto complementar como os outros dois textos analisados, ele está inserido no texto principal do capítulo e chama a atenção por apresentar uma fotografia de um homem coletando lixo em meio a um lixão repleto de urubus. Podemos notar uma abordagem crítica quando o texto fala da grande quantidade de lixo decorrente dos produtos descartáveis que buscam "facilitar" o dia a dia das pessoas. O fato de o texto ter colocado a palavra facilitar entre aspas, permite um debate sobre o tema. Será que esses produtos realmente são elaborados buscando facilitar a vida do consumidor ou o foco principal é a redução de custos e o lucro das empresas? O frag- 
mento do texto é apresentado a seguir: A sociedade de consumo vem aumentando a quantidade de lixo produzido graças aos inúmeros itens descartáveis que procuram "facilitar" o dia a dia das pessoas.

Além do problema gerado pelo lixo dos produtos descartáveis, existem diversos estudos apontando para o fato de que atualmente muitos produtos são fabricados para terem uma vida útil menor, levando o consumidor a comprar um novo produto frequentemente, tal "estratégia" das empresas recebeu o nome de Obsolescência planejada (ou programada). No segundo parágrafo o texto afirma que "o problema do lixo é muito sério”. A partir disso, o texto limita-se a falar as diversas formas de se lidar com o lixo, mas em nenhum momento discute diretamente a relação entre a sociedade capitalista e as práticas sociais que envolvem o consumo como maneira de se inserir nessa sociedade.

O texto afirma que os lixões são inaceitáveis e que existem medidas mais adequadas como os aterros sanitários, a incineração e a compostagem. Essas medidas também têm seus pontos negativos. Ao abordar a questão dos aterros sanitários, o texto cita o capítulo 14. Neste capítulo, que trata do Reino Monera, há um texto complementar na página 208 e 209 com o título "As bactérias podem ajudar a resolver problemas do esgoto e do lixo”. Nesse texto complementar é discutida a importância das bactérias no processo de decomposição da matéria orgânica, o que gera metano. Nos aterros sanitários, o metano é coletado e aproveitado como combustível, o que evita sua emissão diretamente para a atmosfera, exemplificando uma ação alternativa que visa a diminuição da emissão de gases estufa.

É possível notar uma abordagem conservacionista da EA quando o texto fala das populações de baixa renda que exploram os lixões em busca de comida e objetos, pois não cita as questões econômicas e sociais que fazem com que milhares de pessoas precisem retirar seu sustento do lixo. Essas questões econômicas e sociais estão relacionadas com a política do sistema capitalista, que amplifica a lacuna entre as classes sociais e marginaliza as classes mais pobres que não tem acesso à qualificação, emprego e renda.

\section{CONSIDERAÇÕES FINAIS}

Analisando como a EA é abordada no Ensino Médio na disciplina de Biologia, observamos que os livros didáticos analisados apresentam conteúdos referentes à EA, embora muitas vezes essa abordagem não sugira reflexões ou discussões mais profundas nesses temas. Ainda que alguns textos apresentados nos livros analisados mencionem aspectos que poderiam caracterizar uma abordagem crítica da questão ambiental e da EA, notouse que se privilegia uma visão conservacionista, que não considera as questões econômicas, culturais e sociais quando se trabalha a questão ambiental. Notou-se também, em vários momentos, uma visão utilitarista onde a natureza é vista como uma forma de oferecer produtos e recursos para o homem.

Após a análise feita com os dois livros didáticos selecionados, percebeu-se que praticamente todo o conteúdo de EA presente nos livros não faz parte do texto principal. Os conteúdos aparecem dentro de boxes coloridos sendo apresentado como uma informação complementar, extra ou uma curiosidade. Tal fato sugere que esse conteúdo possa ter sido inserido no livro apenas para seguir as recomendações do PCN em relação aos temas transversais. Contudo, Guimarães, Neto e Fernandes (2011) mostram que professores da Escola Básica não utilizam todos os recursos propostos pelo livro didático, porém na maioria dos livros é justamente nas atividades complementares que se encontram propostas de debates, experiências, situações do cotidiano do aluno e textos abordando as questões sociais, culturais, tecnológicas entre outras.

Com relação aos temas dos capítulos, ambos os livros abordam assuntos de forma similar, porém, quando se trata do conteúdo apresentado nos textos complementares nota-se que os livros discutem e problematizam questões diferentes. Sendo assim, ao abordar os ciclos biogeoquímicos, o LD1 escolheu o ciclo do nitrogênio para apresentar um texto complementar (texto: Adubação verde e adubação química), enquanto que o LD2 optou 
por apresentar um texto complementar para o ciclo da água (texto: Escassez da água). Notamos neste exemplo, que os textos principais dos capítulos discutem apenas os aspectos ecológicos, enquanto que a questão ambiental em geral aparece de forma complementar.

A análise mais aprofundada do tema consumo nos capítulos de Ecologia nos permite perceber que há uma discussão ancorada na EA conservadora, desvinculada das questões históricas, sociais, políticas, econômicas e culturais. Não é possível observar uma problematização que vincule as práticas sociais que envolvem o consumo com a sociedade capitalista, que valoriza o lucro e estimula esse consumo. Dessa maneira, a abordagem se torna limitada e não há uma relação entre as questões ambientais com a injustiça social promovida pelo sistema.

Conclui-se que embora as questões ambientais se façam presentes nos livros didáticos, a forma com que esses temas são apresentados não é a que se espera para que possa formar cidadãos ambiental e socialmente conscientes. Não basta apenas mencionar os problemas ambientais, é preciso problematizar o texto de modo a proporcionar ao leitor reflexão sobre a complexidade da temática que está intimamente relacionada além das questões ecológicas com questões, sociais, culturais, econômicas, geográficas e políticas. 


\section{REFERÊNCIAS}

ANACLETO, J. D. R. Jr; CRUZ, D. S. L. da C; DAMIÃO, R. Planejamento familiar. Publicado na Revista do Hospital Universitário Pedro Ernesto, UERJ. Ano 9. Suplemento 2010. Disponível em: http://revista.hupe. uerj.br/detalhe_artigo.asp?id=254. Acesso em: 01 jul. 2014.

BEGON, M.; C.R. TOWNSEND, E; HARPER, J. L. Ecologia: de indivíduos a ecossistemas. 4. ed. Artmed. Porto Alegre. 2007.

BRASIL. Secretaria de Educação Fundamental. Parâmetros curriculares nacionais: Adaptações Curriculares / Secretaria de Educação Fundamental. Secretaria de Educação Especial. - Brasília : MEC /SEF/SEESP. 1998. 62 p.

COSTA, A. P.; COSTA, A. P. Lacunas na abordagem da educação ambiental em livros didáticos de ciências naturais do ensino fundamental 1. VII Congresso Norte e Nordeste de Pesquisa e Inovação. Tocantins. 2012.

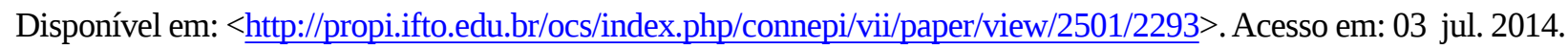

CUNHA, J. M. Crescimento populacional coloca em evidência desigualdades, desafios e oportunidades para o mundo em expansão. 2012. Disponível em: <http://www.ufjf.br/ladem/2012/08/20/crescimentopopulacional-coloca-em-evidencia-desigualdades-desafios-e-oportunidades-para-o-mundo-em-expansao/> . Acesso em: 14 nov. 2015.

FOLADORI, G. O capitalismo e a crise ambiental. Revista Raízes, Ano XVIII, nº 19, maio/1999. Disponível em: <http://www.revistaoutubro.com.br/edicoes/05/out5_08.pdf>. Acesso em: 14 maio 2014.

GERENT, J. A relação Homem-Natureza e suas Interfaces. Cadernos de direito. v. 11. 2011.

GOMES, M.M. P.de L. Conhecimentos ecológicos em livros didáticos de ciências: aspectos sócio históricos de sua constituição. Niterói, RJ, 2008.

GONZÁLEZ-GAUDIANO, E. Imaginario colectivo e ideario de los educadores ambientales en América Latina y el Caribe: ¿Hacia una nueva matriz disciplinaria constituyente? Revista Iberoamericana de Educación. n.40, p.71-89. 2006.

GUIMARÃES, F. M., MEGID-NETO, J., FERNANDES, H.L. Como os professores de $6^{\circ}$ ao $9^{\circ}$ anos usam o livro didático de ciências. Campinas. 2011. Disponível em: <http://www.bibliotecadigital.unicamp.br/ document/?code=000798101>. Acesso: 14 maio 2014.

LAYRARGUES, P. P. Muito além da natureza: Educação ambiental e reprodução social. 2006. Disponível em: <http://www.educacaoambiental.pro.br/victor/biblioteca/LayrarguesEAreproducaosocial.pdf $>$. Acesso em: 10 jun. 2014.

LAYRARGUES, P. P.; LIMA, G. F. C. Mapeando as macro tendências político pedagógicas da educação ambiental contemporânea no Brasil. VI encontro "Pesquisa em educação ambiental". Ribeirão Preto. 2011. Disponível em: <http://www.icmbio.gov.br/educacaoambiental/images/stories/biblioteca/educacao_ambiental/ Layrargues_e_Lima_-_Mapeando_as_macro-tend\%C3\%AAncias_da_EA.pdf $>$.Acesso em: 13 jun. 2014.

LOUREIRO, C. F. B., LAYRARGUES, P. P. Ecologia política, justiça e educação ambiental crítica: perspectivas de aliança contra-hegemônica. Revista Trabalho, Educação e Saúde, Rio de Janeiro, v. 11, n. 1, p. 53-71, jan/ abr., 2013.

LOUREIRO, C.F.B. Sustentabilidade e educação: um olhar da ecologia política. São Paulo. Editora Cortez. 2012. 
LOUREIRO, C.F.B. et. al. Os vários “ecologismos dos pobres” e as relações de dominação no campo ambiental. São Paulo, Editora Cortez. 2009

LOUREIRO, C.F.B Educar, participar e transformar em educação ambiental. Revista brasileira em educação ambiental. Brasília. 2005.

MARTÍNEZ-ALIER, J. O ecologismo dos pobres: conflitos ambientais e linguagens de valoração. São Paulo: Contexto, 2007.

OLIVEIRA, C.S. Educação Ambiental Na Escola: Diálogos Com As Disciplinas Escolares Ciências E Biologia. Dissertação de mestrado. PROGRAMA DE PÓS-GRADUAÇÃO EM EDUCAÇÃO. 123f. 2009.

SANTOS, L.M.F; BOZELLI, R.L; ESPINET, M.; MARTINS, I. Discursos de Educação Ambiental produzidos por professores em formação continuada. Revista Brasileira de Pesquisa em Educação em Ciências, v. 12, n. 2, 2012. Disponível em: < http://revistas.if.usp.br/rbpec/article/view/350/308>. Acesso em: 25 jun. 2014.

SAUVÉ, L. Una Cartografía de Corrientes en Educación Ambiental In: SATO \& CARVALHO. Educação Ambiental: pesquisa e desafios. Porto alegre: Artmed, 2005. p. 17-44.

SILVA, F.A.L. A Formação do(a) educador(a) ambiental nos programas de pós graduação lato sensu das instituições de ensino superior do estado do Rio de Janeiro: uma análise crítica. 2008. 132f. Dissertação de Mestrado (Mestrado em Educação) Faculdade de Educação UFRJ. Rio de Janeiro. 2008.

SILVA, R.L.F.; CAMPINA, N.N. Tipologia de análise de concepções de educação ambiental: Possibilidades e limites para o reconhecimento da pluralidade da área. V Encontro de Pesquisa em Educação Ambiental. Atas... 2009. (CD-Rom).

SORRENTINO.M. De Tbilisi a Thessaloniki: a EA no Brasil In: QUINTAS, J.S. (org.) Pensando e praticando a educação ambiental na gestão do meio ambiente. Brasília: Ibama, 2002. p.105-114. (Coleção Meio Ambiente, Série Educação Ambiental. v. 3). 